\title{
Designing Shock Absorbing Composites by Impregnating Woven Fabrics with Shear Thickening Fluids
}

\author{
Aaditya Saha ${ }^{1}$ and Fred Avett ${ }^{1 \#}$ \\ ${ }^{1}$ Chamblee Charter High School, Chamblee, GA, USA \\ \#Teacher
}

\section{ABSTRACT}

Millions of sports and recreation-related injuries occur each year. Different shock-absorbing solutions, such as polyethylene and polyurethane foams, are used in helmets and protective equipment, but one area most sports-gear manufacturers have not explored is the usage of shear thickening fluids (STFs). An STF is a material that is soft under normal conditions but acts rigid when stressed or pressured. STF composites were fabricated and tested with the goal of exploring their viability for use in shock-absorption applications, especially for sports. The role of fabric- and particle-type, particle-to-carrier fluid ratios, nano-particle additives, and the thickness of the composite were studied, and were all hypothesized to have an effect on the impact-resistance of the fabricated STF-composites. Drop-tests were conducted by releasing a 1.1-lb. weight from an electromagnet onto the composites. An impact-force sensor was placed underneath. The weight and height of the drop were chosen to simulate the hardest recorded NFL hit. All hypothesized factors were found to affect impact resistance. The combination of nylon-fabric impregnated by an STF mix of propylene-glycol and silica-nanoparticles, with a cerium-oxide nano-particle additive, displayed better shockabsorption behavior than other fabricated composites. All of the STF-composites also outperformed tested commercial shock-absorption materials despite being thinner and more flexible. These results demonstrate the potential of using STF-impregnated textile fabrics for protective composites for sportswear, as well as for non-sport shock-absorption applications, like in military vests and helmets, and aerospace applications. Further research is necessary to work towards a final product which can be used.

\section{Introduction}

Youth sports in America are on the rise every year, and so are the injuries associated with participation in sports and recreation activities. 2.6 million of sports-related doctor visits between 1997-1998 were aged 5-24 years (1). Within a decade, the number of sports induced injuries accounted for in the ER shot up to 4.3 million (2). It is estimated that in 2011, more than 46.5 million children played team sports and from 2011 through 2014, Americans aged 5 years and over sustained an average 8.6 million sports-and recreational-related injury episodes per year (3). The common injuries to bodies at different body parts, and the number of injuries among athletes 19 and under from 10 popular sports are provided as shown in Figure $1(4,5)$ :
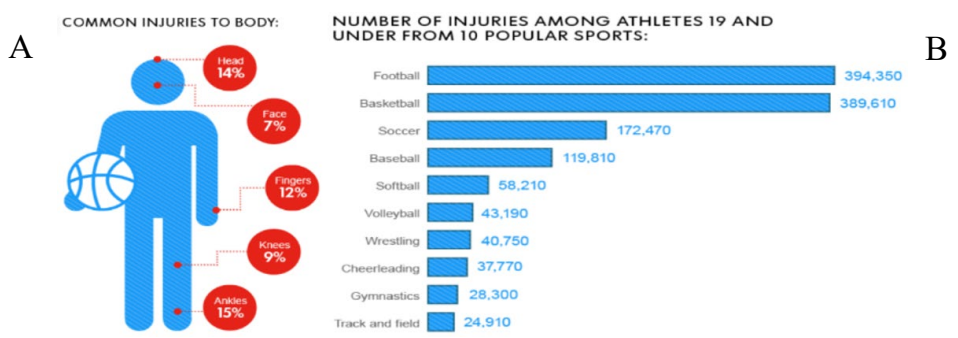

Figure 1. Common Sports Injuries to Different Body Parts (1a) and Number of Injuries in Various Sports (1b). 
The story is no different in professional sports; this is evident from the most recent injury data released by the NFL on January 26, 2018 that includes statistics on a broad range of injuries including incidences of reported concussions in the preseason, regular season, and postseason from 2012-2017 (6). See Figure 2 below.

\begin{tabular}{|c|c|c|c|c|c|c|c|c|c|}
\hline \multirow{2}{*}{ Year } & \multicolumn{4}{|c|}{ Preseason } & \multicolumn{3}{c|}{ Regular Season + Postseason } & \multicolumn{3}{c|}{ Full Season } \\
\cline { 2 - 11 } & Practice & Game & Total & Practice & Game & Total & Practice & Game & Total \\
\hline $\mathbf{2 0 1 2}$ & 42 & 43 & $\mathbf{8 5}$ & 3 & 177 & $\mathbf{1 8 0}$ & 45 & 220 & $\mathbf{2 6 5}$ \\
\hline $\mathbf{2 0 1 3}$ & 39 & 38 & $\mathbf{7 7}$ & 4 & 163 & $\mathbf{1 6 7}$ & 43 & 201 & $\mathbf{2 4 4}$ \\
\hline $\mathbf{2 0 1 4}$ & 42 & 41 & $\mathbf{8 3}$ & 8 & 121 & $\mathbf{1 2 9}$ & 50 & 162 & $\mathbf{2 1 2}$ \\
\hline $\mathbf{2 0 1 5}$ & 29 & 54 & $\mathbf{8 3}$ & 9 & 187 & $\mathbf{1 9 6}$ & 38 & 241 & $\mathbf{2 7 9}$ \\
\hline $\mathbf{2 0 1 6}$ & 26 & 45 & $\mathbf{7 1}$ & 7 & 172 & $\mathbf{1 7 9}$ & 33 & 217 & $\mathbf{2 5 0}$ \\
\hline $\mathbf{2 0 1 7}$ & 45 & 46 & $\mathbf{9 1}$ & 11 & 189 & $\mathbf{2 0 0}$ & 56 & 235 & $\mathbf{2 9 1}$ \\
\hline
\end{tabular}

Figure 2. Table of concussions in the NFL from 2012-17.

Concussion rates are even higher at lower levels because top-of-the line helmets are not affordable. It is estimated that 67,000 concussions occur annually in high-school football (7). Hits to head could result not only in concussions but also long-term brain damage. This problem also extends to other sports, like baseball, hockey, lacrosse, and more (7). The following Figure 3 shows the number of concussions among youth athletes from 10 popular sports (4).

\section{NUMBER OF CONCUSSIONS AMONG ATHLETES 19 AND UNDER FROM 10 POPULAR SPORTS:}

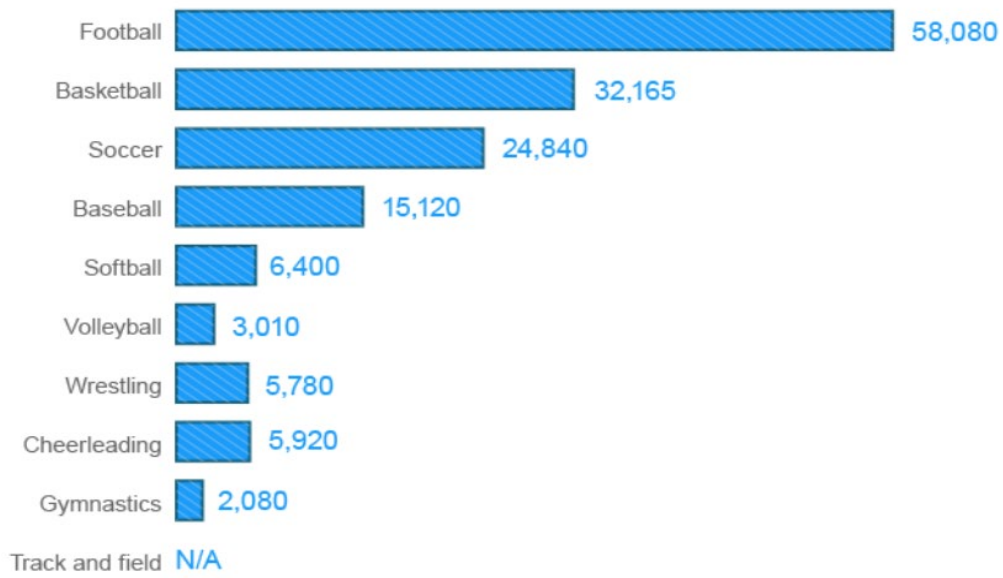

Figure 3. Number of Concussions in Various Sports.

Based on all the sport injury data, it is very clear that designs and materials used to construct helmets and protective gears across the sports and recreational industry need improvement.

Shear thickening Fluids or STFs, also known as dilatant materials, have hardly been explored in impact protection sports gear despite their potential. An STF material is soft when stirred gently or gently played with but turns hard when stressed or pressured. STF material systems can be "particle based" or "non-particle based". STFs are probably most known due to shear thickening Oobleck - a mix of cornstarch and water. The shear thickening properties 
of this particle-based system were explored comprehensively by researchers at Cornell and Edinburgh, who found that in particle based STFs, shear thickening occurs due to friction between particles (8). Another theory which explains the behavior of particle-based shear thickening fluids is the order-disorder theory, which states that below a critical shear rate, particles in suspension are in a layered order, but beyond a critical shear rate, hydrodynamic forces acting on the particles become stronger, and the layered orientation is disrupted, and there is a drastic increase in suspension viscosity (9). Dilatancy in non-particle-based systems is due to the structure of the polymer chain. Silly Putty and D3O, the two most common STFs besides Oobleck, are both non-particle-based STFs and their shear thickening action is achieved through chemistry.

While the concentration of particles has been shown in Oobleck to have an effect on the viscosity, scientists have not yet comprehensively studied its shock absorption properties (10). STF and composites are mostly being researched as component material in "Liquid armor" for the military and law-enforcement in low-mass high-velocity impacts (especially for bullet-proof materials) (11). A recent study found that Kevlar (a bullet-proof fabric) could be stab proof by impregnating it with an STF, making it suitable for body armor (12). In addition, D3O, a non-particle based STF is also being used in football helmets. However, particle based STF technology is not currently applied in any sports gear.

The purpose of this project was to explore whether it is viable to use particle-based shear thickening composites for shock absorption applications, especially in protective gear for sports, by testing and optimizing their impact resistance properties.

One area of assessment of STFs should be whether changing the concentrations or ratios between solid and liquid components of particle-based shear thickening material makes any difference at all. Two additional factors that may be critical to STF composites are the type of particle that is suspended in STF and the fabric that is being impregnated by the STF.

Additionally, the effect of additives on the performance of STFs (or rather, whether they enhance the performance) should be investigated thoroughly (12).

In college level football, the 95th percentile peak linear acceleration during collisions of hits is $62.7 \mathrm{~g}$ (14). However, athletes often shy away from using protection gear if they think it hinders their performance. Hence, even though it seems logical that increased thickness of padding material will increase performance, shock absorbing composites to be used in helmets and sports gear need to strike a balance between having good shock-absorbing characteristics and being light and thin.

\section{Hypothesis}

Shear Thickening Fluids will enhance shock absorption in protective composites used in sports gear, and withstand hits from large mass bodies, moving at a relatively low velocity in comparison to bullets.

The performance of shock absorbing composites that use shear thickening material can be altered by choosing different types of woven fabrics to be impregnated, types of particles in the STF, particle to "carrier liquid" proportions, thicknesses of the composite, and additives in the STF, which will increase the viscosity, and as a result, enhance the performance. 


\section{Materials}

\begin{tabular}{|c|c|c|c|c|c|c|}
\hline \multicolumn{7}{|c|}{$\begin{array}{l}\text { Test Objective: Determine whether shock absorption behavior of composites using shear thickening fluids are affected } \\
\text { by fabric types with various tensile strengths, and different suspended particles }\end{array}$} \\
\hline $\begin{array}{l}\text { Fabric Type with } \\
\text { different Tensile } \\
\text { Strengths } \\
\text { (with Mix 1) }\end{array}$ & $\begin{array}{l}\text { Carbon Fiber } \\
\text { immpregnated } \\
\text { with clay-PG } \\
\text { Mix } 1 \text { STF } \\
\\
\text { Thickness = } \\
0.5 \mathrm{~cm}\end{array}$ & $\begin{array}{l}\text { Carbon Fiber } \\
\text { impregnated } \\
\text { with silica-PG } \\
\text { Mix } 1 \text { STF } \\
\text { Thickness = } \\
0.5 \mathrm{~cm}\end{array}$ & $\begin{array}{l}\text { Kevlar Fiber } \\
\text { impregnated } \\
\text { with clay-PG } \\
\text { Mix 1 STF }\end{array}$ & $\begin{array}{l}\text { Kevlar Fiber } \\
\text { impregnated } \\
\text { with silica-PG } \\
\text { Mix } 1 \text { STF }\end{array}$ & $\begin{array}{l}\text { Nylon Fiber } \\
\text { impregnated } \\
\text { with clay-PG } \\
\text { Mix } 1 \text { STF }\end{array}$ & $\begin{array}{l}\text { Nylon Fiber } \\
\text { impregnated } \\
\text { with silica-PG } \\
\text { Mix } 1 \text { STF }\end{array}$ \\
\hline \multicolumn{7}{|c|}{$\begin{array}{l}\text { Test Objective: Determine whether shock absorption behavior of composites using shear thickening fluids are affected } \\
\text { by the particle/carrier fluid mix ratio in STFs }\end{array}$} \\
\hline $\begin{array}{l}\text { STF Mix } \\
\text { (with Mix 2) }\end{array}$ & \multicolumn{3}{|c|}{$\begin{array}{l}\text { Picked the best specimen from the above tests } \\
\text { (found to be Nylon Fiber impregnated with } \\
\text { silica-PG). Use a STF mix with a different } \\
\text { composition of particle and PG. } \\
\text { Mix } 2 \text { STF } \\
\text { Thickness }=0.5 \mathrm{~cm}\end{array}$} & \multicolumn{3}{|c|}{$\begin{array}{l}\text { Picked the best specimen from the above tests } \\
\text { (found to be Nylon Fiber impregnated with } \\
\text { silica-PG). Use a STF mix with a different } \\
\text { composition of particle and PG. } \\
\text { Mix } 2 \text { STF } \\
\text { Thickness }=1.0 \mathrm{~cm}\end{array}$} \\
\hline \multicolumn{7}{|c|}{ Test Objective: Investigate whether increase thickness will enhance the impact resistance of STF composites } \\
\hline Thickness & \multicolumn{2}{|c|}{$\begin{array}{l}\text { Carbon Fiber impregnated with } \\
\text { silica-PG } \\
\text { Mix } 1 \text { STF }\end{array}$} & \multicolumn{2}{|c|}{$\begin{array}{l}\text { Kevlar Fiber impregnated with } \\
\text { silica-PG } \\
\text { Mix } 1 \text { STF }\end{array}$} & \multicolumn{2}{|c|}{$\begin{array}{l}\text { Nylon Fiber impregnated with } \\
\text { silica-PG } \\
\text { Mix } 1 \text { STF }\end{array}$} \\
\hline \multicolumn{7}{|c|}{ Test Objective: Evaluate whether additives increase the impact resistance of STF composites } \\
\hline $\begin{array}{l}\text { Additive } \\
\text { Cerium Oxide } \\
\text { (12) }\end{array}$ & \multicolumn{6}{|c|}{$\begin{array}{l}\text { Picked the best specimen from the above tests (found to be Nylon Fiber impregnated with sili } \\
\text { at } 1 \mathrm{~cm} \text { ). Add cerium oxide Additive in the mix }\end{array}$} \\
\hline \multicolumn{7}{|c|}{$\begin{array}{l}\text { Test Objective: Compare shock absorbing behavior of shear thickening composites with commercially available } \\
\text { proprietary shock absorbing materials }\end{array}$} \\
\hline $\begin{array}{l}\text { Proprietary } \\
\text { Material }\end{array}$ & $\begin{array}{l}\text { Poron } \\
\text { Thickness = } \\
0.5 \mathrm{~cm}\end{array}$ & $\begin{array}{l}\text { Poron } \\
\text { Thickness = } \\
1.0 \mathrm{~cm}\end{array}$ & $\begin{array}{l}\text { D30 } \\
\text { Thickness = } \\
0.5 \mathrm{~cm}\end{array}$ & $\begin{array}{l}\text { D30 } \\
\text { Thickness = } \\
1.0 \mathrm{~cm}\end{array}$ & $\begin{array}{l}\text { Sorbothane } \\
\text { Thickness = } \\
0.5 \mathrm{~cm}\end{array}$ & $\begin{array}{l}\text { Sorbothane } \\
\text { Thickness = } \\
1.0 \mathrm{~cm}\end{array}$ \\
\hline
\end{tabular}

Figure 4. Experimental Matrix detailing all performed experiments.

Materials were selected to effectively study the effect of the types of fabric impregnated, types of particles in the STF, particle to "carrier liquid" proportions, thickness, and additives. Carbon Fiber, Kevlar and Nylon were impregnated to create composite samples. These composite Structures were fabricated by layering an STF mix between sheets of fabrics. Clay and Silica nanoparticles were chosen to be mixed with propylene glycol (PG) to create different STFs (11). It was made primary focus that in all of the STFs, the proportion of solid particles is sufficient enough to display shear thickening properties (15). Therefore, for mix 1, the STF composite had a 5:1 ratio of solid particles to PG (1 cup of Silica was mixed with $48 \mathrm{~mL}$ of PG), whereas for mix 2, they had a 4:1 particle to PG ratio ( 1 cup of silica was mixed with $60 \mathrm{~mL}$ of PG). Equal amount of STF was added to each layer, and the STF composite was pressed hard, so that the STFs would intercalate with fabric. The STFs were also spread evenly across the fabric.

\section{Methods}

A drop test setup (16) was assembled to evaluate the impact resistance abilities of the composites shown in the matrix (Figure 4), to determine whether or not shear thickening fluids can perform better than materials currently used in sports. This method was determined to be the easiest and most direct way to test the potential padding materials with different varied factors against each other. Materials for the drop test setup as well as the ingredients for the composites 
to be designed were procured. A drop test tower (metal stand) was constructed, and a shelf with a central hole was placed 4 feet above the ground. An electromagnet of diameter 1 3/4" with 88 pounds of holding capacity was attached to a metal plate through a nut and bolt, and was placed above the shelf, so that electromagnet protrudes through the central hole. The electromagnet was attached to a power source, allowing a spherical 1.1-pound $(0.5 \mathrm{~kg})$ weight to be held by the magnet. When the power is turned off, the electromagnet releases the weight onto the specimen, which was placed on an impact force sensor, that had been procured from Loadstar Sensors. This electromagnet procedure was chosen in order to eliminate any human error when dropping the weight. The weight was determined to be circular to eliminate error in the drop. The weight and height of the drop was determined to be $0.5 \mathrm{~kg}$, dropped from 4 feet, to simulate the maximum NFL hit of 1600 pound-forces.

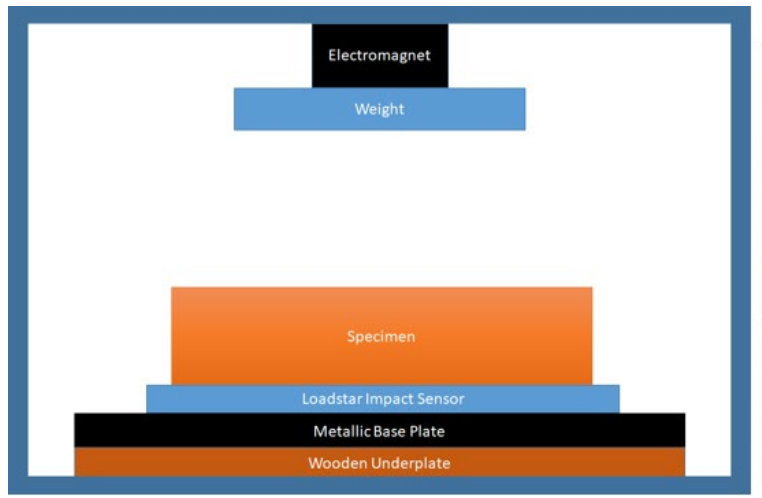

B

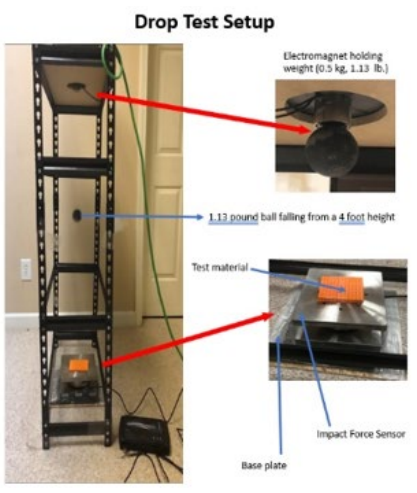

Figure 5. - Drop Test Schematic (5a) and Setup (5b)

The Loadstar sensor was used for "dynamic force measurement solution", as it is usually used for applications that require force information to be collected at a high data rate. The Impact Force Sensor was connected to the USB interface, which connects to a computer. Dynamic Force is captured by the sensor and transmitted through USB interface to the $10 \mathrm{~K}$ LoadVUE software, to display the impact output (17).

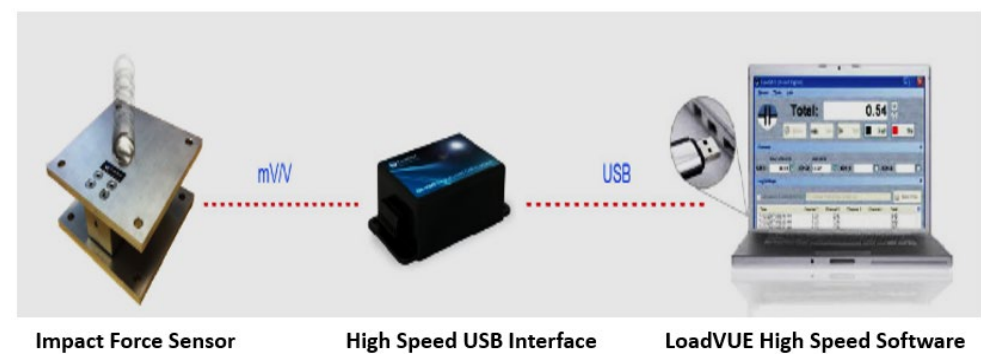

Figure 6. Impact Force Sensor sending data to software (17). 


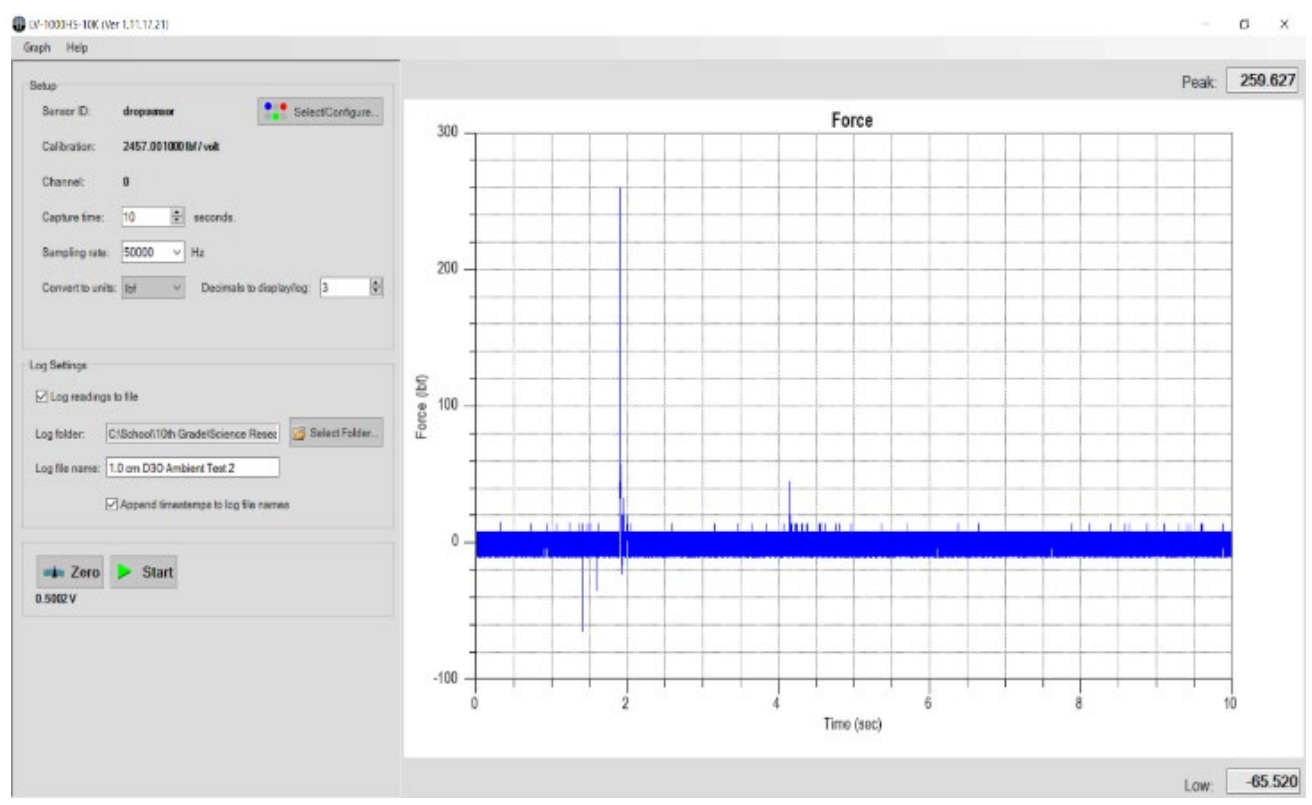

Figure 7. Screenshot of LoadVUE software.

After drop testing, the data value given by the LoadVUE software was recorded in a spreadsheet. The data value was received as a measurement in pounds-force (lbf). Prior to conducting all drop tests on samples, a metal-tometal drop test was performed with no sample directly on the sensor plate. In order to calculate the impact resistance percentage of each shock absorbing material, the value received from the material test was compared to the value from the metal-to-metal (no-sample) test.

Equation 1: This formula was used to calculate the Impact Resistance percentage for each sample.

Impact Resistance $\%=($ Metal to Metal test - Peak Impact Force $) /$ Metal to Metal test

\section{Results}

The first test that was performed was the "Silica Mix 1" STF with no fabric impregnation. This test was performed as a baseline, to see the contribution of the fabric to the designed STF composite mix.

The first group of six tests were the "Mix 1" composites (5:1 solid to liquid ratio in the shear thickening fluid mixture), varying fabric (Carbon Fiber, Kevlar, and Nylon) and particle type (silica, clay). The three types of fabrics and two types of particles were tested in all possible permutations, in order to see which produced the best result.

After performing these tests, the results showed that the composite with Nylon fabric and Silica particles had the best impact resistance performance $(90.7 \%)$ of the six that were tested. As a result, this combination was singled out to be modified, in order to test the variable of particle-to-carrier ratio. In this next group of materials, the ratio was lowered from 5:1 to 4:1, meaning that less silica particles were used in the fabrication process of the composites. A $0.5 \mathrm{~cm}$ thickness composite was compared to the previous group, and a $1 \mathrm{~cm}$ composite was also fabricated.

The three $0.5 \mathrm{~cm}$ Mix 1 composites, as well as the Mix 2 composite, were then all increased to $1 \mathrm{~cm}$ to measure the effect of thickness of the composite on impact resistance percentage.

Of all the composites tested under these parameters, the " $1 \mathrm{~cm}$ Nylon and the Silica Mix 1" composite performed the best $(91.2 \%)$. The final variable to measure was whether a nano-particle additive could increase the impact resistance percentage. Originally, it was attempted to add the cerium oxide (ceria) additive in with the Nylon + Silica 
Mix 1 composite. However, this composite was too dense to contain both nanoparticles, and therefore the 4:1 silica to PG ratio was used with the ceria additive. Finally, three different commercial shock absorbing materials (Sorbothane, Poron, and D3O) were tested at 0.5 and $1 \mathrm{~cm}$ to compare with the shear thickening fluid composites. Table 1 displays the results that were recorded by the LoadVUE Software.

Table 1. A representation of all the performed experiments.

\begin{tabular}{|c|c|c|c|}
\hline Exp \# & Specimen & Impact Force & $\%$ of Impact Resistance \\
\hline 1 & Metal to Metal & 1534.5 & 0 \\
\hline 2 & Silica Mix 1 with no Fabric $(1 \mathrm{~cm})$ & 672.69 & 56.2 \\
\hline 3 & Carbon Fiber + Clay Mix $1(0.5 \mathrm{~cm})$ & 282.57 & 81.6 \\
\hline 4 & Kevlar + Clay Mix $1(0.5 \mathrm{~cm})$ & 333.74 & 78.3 \\
\hline 5 & Nylon + Clay Mix $1(0.5 \mathrm{~cm})$ & 281.41 & 81.7 \\
\hline 6 & Carbon Fiber + Silica Mix $1(0.5 \mathrm{~cm})$ & 149.08 & 90.3 \\
\hline 7 & Kevlar + Silica Mix $1(0.5 \mathrm{~cm})$ & 162.27 & 89.4 \\
\hline 8 & Nylon + Silica Mix $1(0.5 \mathrm{~cm})$ & 143.43 & 90.7 \\
\hline 9 & Nylon + Silica Mix $2(0.5 \mathrm{~cm})$ & 521.34 & 66.0 \\
\hline 10 & Nylon + Silica Mix $2(1 \mathrm{~cm})$ & 238 & 84.5 \\
\hline 11 & Carbon Fiber + Silica Mix $1(1 \mathrm{~cm})$ & 143.56 & 90.6 \\
\hline 12 & Kevlar + Silica Mix $1(1 \mathrm{~cm})$ & 153.89 & 90.0 \\
\hline 13 & Nylon + Silica Mix $1(1 \mathrm{~cm})$ & 135.03 & 91.2 \\
\hline 14 & Nylon + Silica Mix $2+$ Cerium Oxide Additive $(1 \mathrm{~cm})$ & 112 & 92.7 \\
\hline 15 & Poron $(0.5 \mathrm{~cm})$ & 830.72 & 45.9 \\
\hline 16 & Poron $(1 \mathrm{~cm})$ & 502 & 67.3 \\
\hline 17 & $\mathrm{D} 3 \mathrm{O}(0.8 \mathrm{~cm})$ & 494.71 & 67.8 \\
\hline 18 & $\mathrm{D} 3 \mathrm{O}(1 \mathrm{~cm})$ & 261.22 & 83.0 \\
\hline 19 & Sorbothane $(0.625 \mathrm{~cm})$ & 396.46 & 74.2 \\
\hline 20 & Sorbothane $(1.25 \mathrm{~cm})$ & 214.01 & 86.1 \\
\hline
\end{tabular}

These results have been plotted in a bar graph in order to better visualize the data. This graph is shown below.

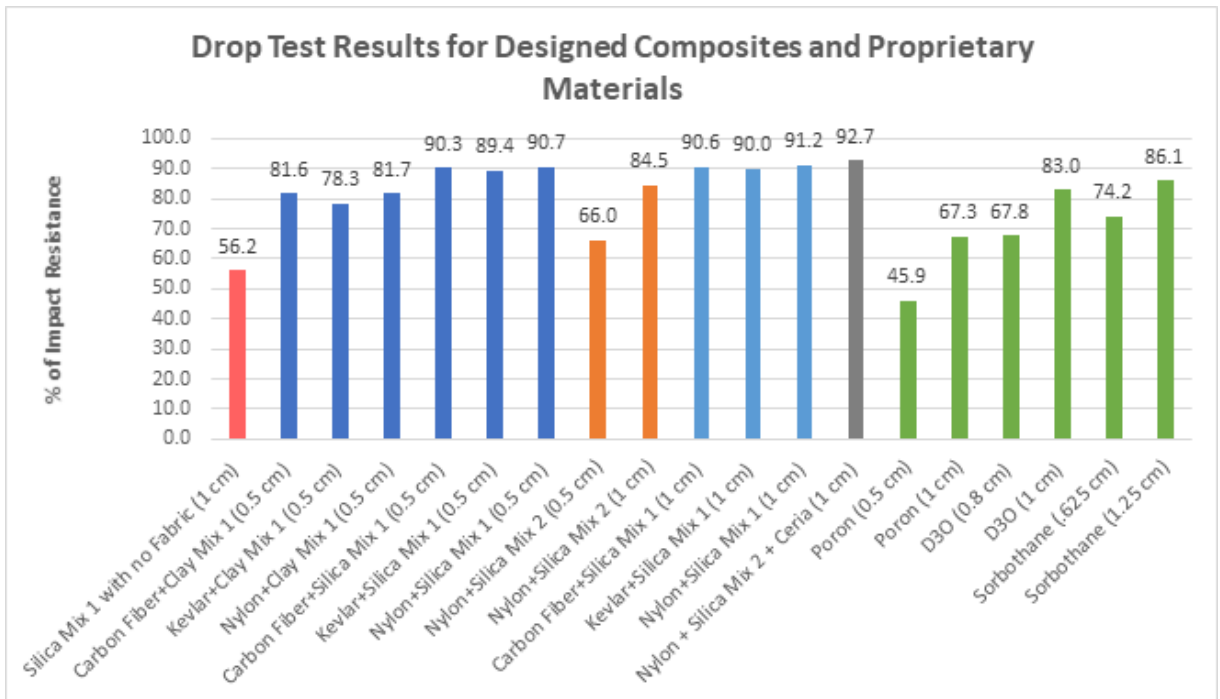

Figure 8. A graphical representation of all the performed experiments. 
The bars were color-coded based on the experimental matrix (Figure 4). The first group (Mix 1) is dark blue, Mix 2 is orange, Group 3 which measured thickness is light blue, the additive test is gray, and all of the commercial materials are green. The $y$-axis shows the $\%$ of impact resistance, and these results are also displayed at the top of each bar.

\section{Discussion of Results}

From the graph above (Figure 8), it could be observed that all of the designed Shear Thickening Composites performed better than or very comparable to three tested proprietary materials (Poron, D3O, and Sorbothane) currently available in the market which are popularly used in various sport and non-sport applications. Based on these results, it would be reasonable to conclude that the materials used today for shock absorption applications can be replaced by particle based STF composites.

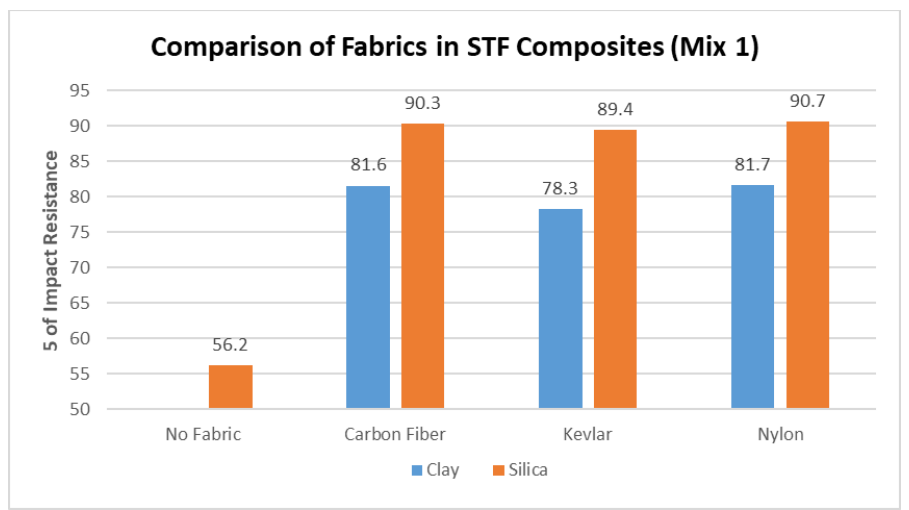

Figure 9. A comparison of the Impregnated Fabrics.

From Figure 9, it is evident that all three fabrics performed in a similar range. These results indicate that tensile strength of the fabric does not matter too much for impact resistance of the tested STF composites. However, having a fabric in the STF composite is important, as indicated by the first bar in the graph, which shows that all the STF composites without fabrics had a lower impact resistance than the STF with fabrics. It points to the fact that the intercalation between fabric and the STF mix is more important than tensile strength.

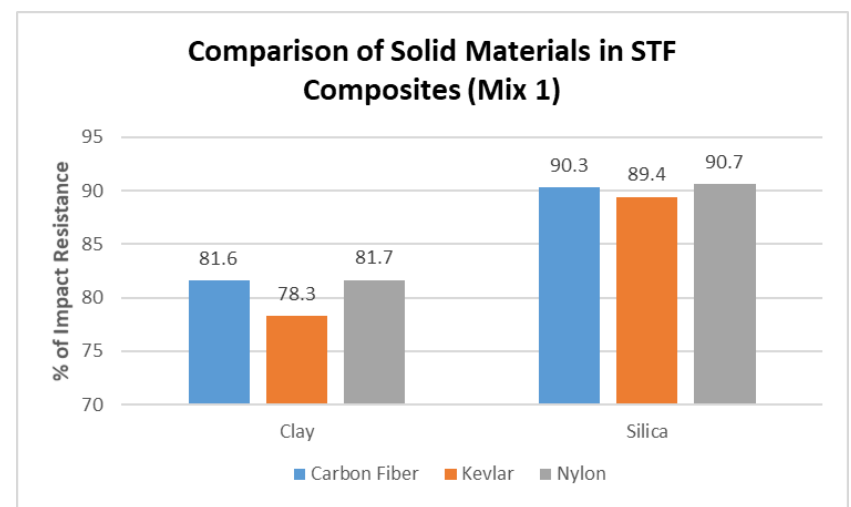

Figure 10. A comparison of the Solid Materials in the STF mix.

From Figure 10, it is also clear that Silica performed better than clay, as all three tests with different fabrics yielded lower impact forces for the Silica STF. In both the Clay and Silica STF Mix 1 tests, a Particle to PG ratio of 
5:1 was maintained, and therefore the two tests are very comparable. However, it should be noted that the Clay STFs where observably more fluid than the Silica STFs.

Based on these results, the Nylon and Silica STF Composite was selected to perform further tests, since Nylon is more cost-effective than the other two fabrics. More tests on Nylon and Silica STF Composites with different Particle to PG ratios were carried out.

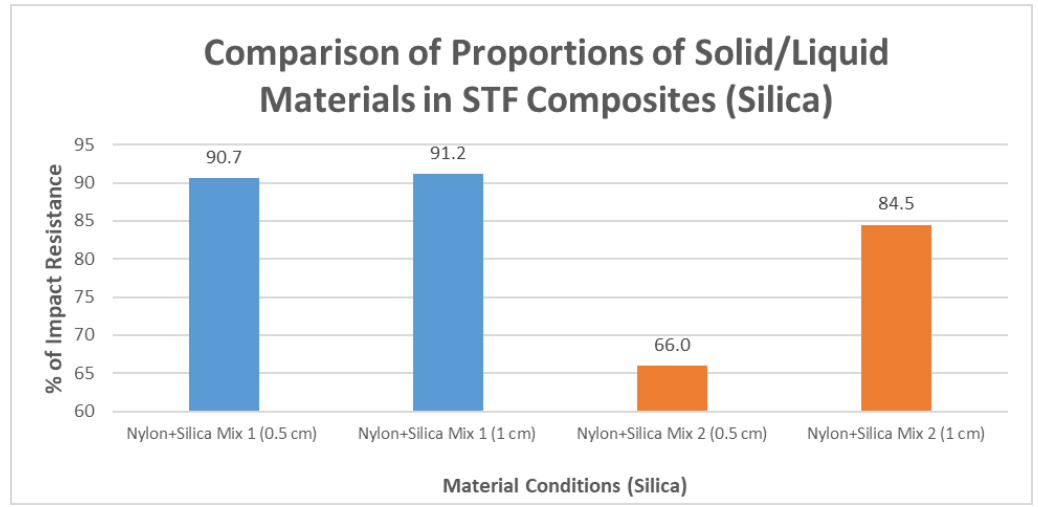

Figure 11. A comparison of the STFs with different STF mixes in 0.5 and $1 \mathrm{~cm}$ thickness.

As shown in Figure 11, $0.5 \mathrm{~cm}$ Silica PG Mix 1 composite performed much better (\% impact resistance of 90.7) than $0.5 \mathrm{~cm}$ Silica PG Mix 2 composite (\% impact resistance of 66.0). It should be noted that the difference in performance was much closer in $1.0 \mathrm{~cm}$ composites (\% impact resistance $91.2 \mathrm{vs} 84.5$ ). From these tests, it is clear that higher proportions of solid components compared to liquid components are more effective in Shear Thickening Fluids being used as shock absorbing materials probably owing to a larger "hydro clustering" effect of particles in stable suspension within the propylene glycol carrier fluid.

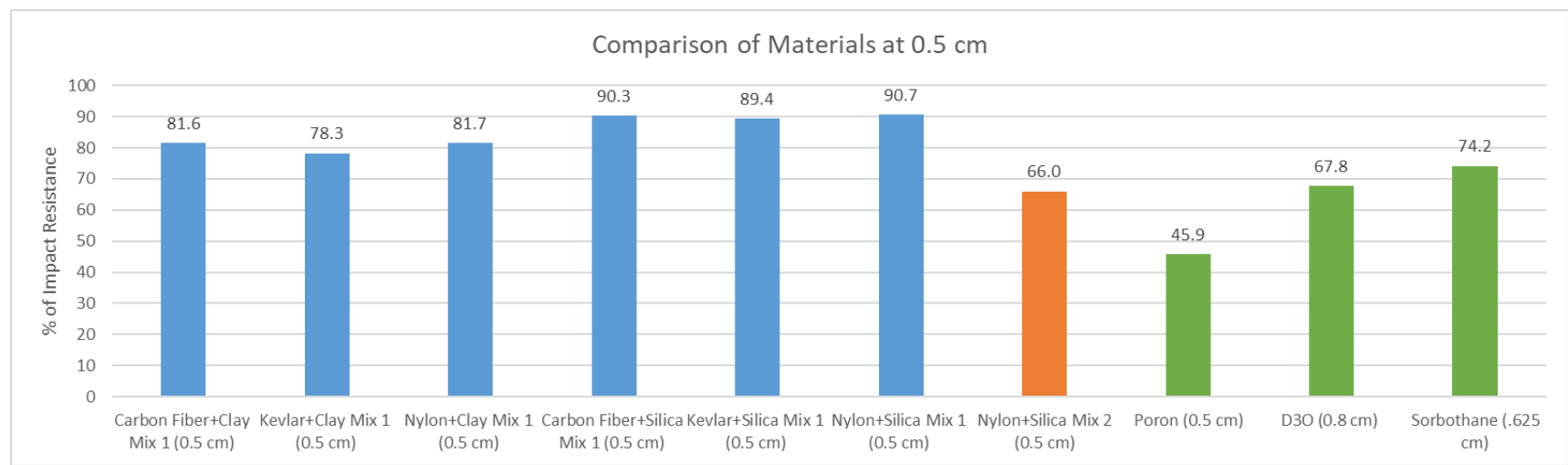

Figure 12. The results for the $0.5 \mathrm{~cm}$ test specimens. 


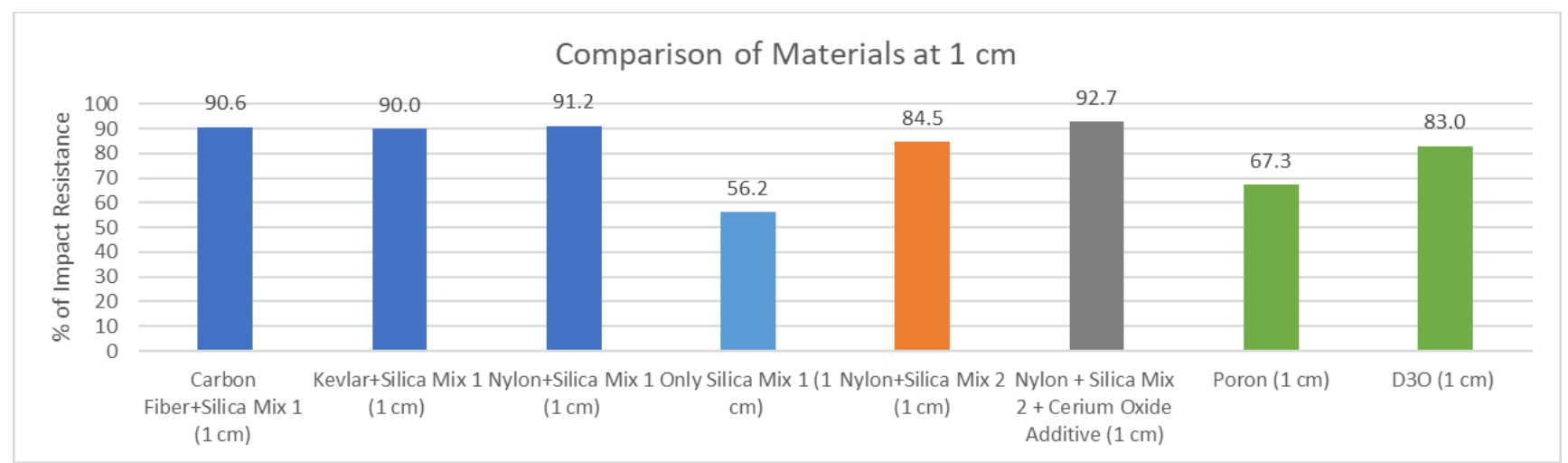

Figure 13. The results for the $1.0 \mathrm{~cm}$ test specimens.

Thickness was also tested as a variable. It was observed from Figures 12 and 13 that impact resistance increases with an increase in thickness. The percentage of impact resistance varied from 66 to $84.5 \%$ in the Nylon Silica Mix 2 composite, which is an appreciable increase in performance. However, in Mix 1, the STF composites that were tested in both thicknesses barely increased (less than $1 \%$ ) with the $0.5 \mathrm{~cm}$ increase in thickness. It also should be noted from Figures 12 and 13 that a similar phenomenon occurred in the proprietary materials. In Poron, the percentage of impact resistance increased from 46 to $67.3 \%$, and D3O improved from 67.8 to $83 \%$, whereas Sorbothane only increased from 74.2 to $86.1 \%$. These results show thickness does affect the performance of an STF composite or shock absorbing material. However, we can infer that each specimen has a certain threshold level of thickness. Once it is reached, increasing the thickness will not proportionally increase the performance of the composite/material.

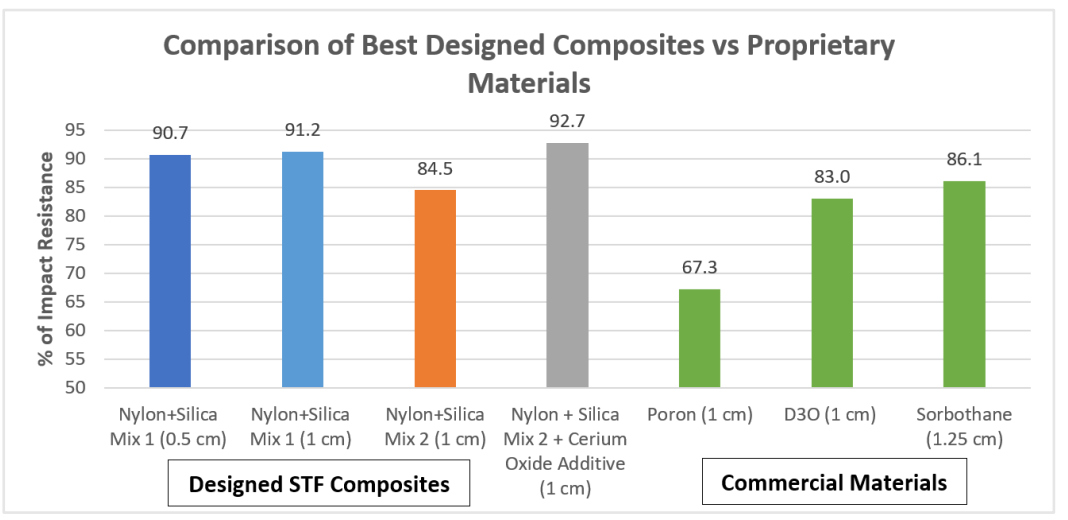

Figure 14. Synthesized Comparison of Best STF Composites and Proprietary Materials.

The best performing STF composites that were designed in this project were compared to proprietary shock absorbing padding materials available in the market in Figure 14. It has been observed that the Nylon and Silica PG Mix 2 with the Cerium Oxide additive performed better than all other composites. The additive increased the performance of the Mix 2 STF composite by around 10\%, which was extremely impressive, considering that Mix 2 (with no additive) already performed better than D30, supposedly one of the best padding materials currently used in professional football helmets, and other sports and non-sports applications. This is most likely due to the fact that Cerium Oxide increases the viscosity of the Silica-PG STF (16). It may be inferred from the results that STFs with higher maximum viscosities will perform much better than those with lower maximum viscosities for high mass low velocity impact. It is interesting to note that despite being at most half as thick, the Nylon Silica PG mix $1(0.5 \mathrm{~cm})$ outperformed all the proprietary materials tested - Poron $(1 \mathrm{~cm})$ by $35 \%$, D3O $(1 \mathrm{~cm})$ by $8 \%$, and Sorbothane $(1.25 \mathrm{~cm})$ by $5 \%$. Looking at these results, it is worth performing more testing on Shear Thickening Fluid composites to determine their effectiveness for both sports and non-sports shock absorbing applications. 


\section{Conclusion}

Based on work conducted in this project, for high-mass-low-velocity impacts it was concluded that tensile strength plays a less significant role as compared to the degree of intercalation between an STF and fabric material in the shock absorption properties of impregnated fabrics. This theory explains why STF composites created with a fabric performed a lot better than composites made without a fabric. While the type of woven fabric that was impregnated was found to be relatively insignificant to impact resistance, the presence of some type of fabric was found to be important.

As hypothesized, the results showed that shear thickening properties are very dependent on particle type and particle to liquid ratios in STF mixes. The tests with the Silica and Clay STF composites showed that particle type has a large effect on impact resistance, since the Silica STFs outperformed the Clay STFs in every test. Better shock absorption properties through shear thickening behavior are achieved in STF mixes with higher solid to liquid ratios, which is shown by the comparison of the two mixes with different proportions of silica and PG.

It was also observed that until a certain point, thickness is very important, but once a certain threshold thickness (which is different for all STFs) is reached, performance is largely unaffected.

Finally, it was observed the use of small amounts of Cerium Oxide massively increased the performance of a composite made by impregnating Nylon with a Silica-PG STF mix.

STF composites showed enormous potential to replace existing padding materials used in various shock absorbing applications. More experiments should be performed on additional additives, as well as more fabrics and particle types, in order to truly find the best possible STF composite.

This project has a lot of future applications; it can be used in any industry that requires shock absorption. Examples include in the sports industry (which was the focus and inspiration of the project), in the aerospace industry, in the construction industry, and in the transportation industry. The results of this project show that this STF composite can be used in any application where the compared materials are currently used. Further research can be performed to develop a physics-based phenomenological model to improve composite design and fabrication, put in-situ electronic sensors in these STF composite systems for more accurate simulations of shock absorption performance in actual field applications. Specifically looking at the industrial applications, more work needs to be done in order to create a final product which can be used in many sports and non-sports applications where shock absorbing materials are required (e.g., protective sports equipment, military vests and helmets, and aerospace applications).

\section{Limitations}

There were a couple of limitations to this project. Firstly, due to budgetary constraints, the STF composites had to be created manually. This process could have been improved by using an automated mechanical mixer and impregnating presser, which would create more consistently uniform STF mixes. To ensure that this limitation would not affect the outcome of the experiment, there were quality controls in place (for example, timing each mix and observing the texture of the STF mix), and all experiments were repeated multiple times to eliminate any outliers in the data. However, because the procedure may have been prone to human error and was very labor intensive, more work needs to be done to improve this process.

Secondly, the opportunity to use instruments like a viscometer or an electron microscope, which are usually accessible in a scientific lab, was not available since all work was performed in a home lab setup. While this did not affect the outcome, the results could be better understood if these instruments were available. 


\section{Acknowledgements}

The above research was performed in a home setup over the past year. I would like to thank Dr. Murali Gopal Muraleedharan, for giving me valuable technical guidance and advice and access to certain academic papers. I would also like to thank Loadstar Sensors for selling their impact force sensor at a discounted price.

\section{References}

1. Burt, C. W., \& Overpeck, M. D. (2001). Emergency visits for sports-related injuries. Annals of emergency medicine, 37(3), 301-308.

2. Geier, D (2011, August 3). Sobering Statistics About Youth Sports and Injuries. Retrieved March 16, 2016, from The Post and Courier Website.

3. National Sporting Goods Association. (2011). 2011 versus 2001 youth sports participation, NSGA. Retrieved from http://www.nsga.org/files/public/2011vs2001_youth_participation_website. pdf

4. Sheu, Y., Chen, L.-H., \&amp; Hedegaard, H. (2016). Sport and Recreation related Injury episodes in The U.S. Population. Medicine \&amp; Science in Sports \&amp; Exercise, 48, 868. https://doi.org/10.1249/01.mss.0000487603.12911.c4

5. Healy, M. (2013, August 6). 1.35 million youths a year have serious sports injuries. USA Today. https://www.usatoday.com/story/news/nation/2013/08/06/injuries-athletes-kids-sports/2612429/.

6. NFL. (2020, December 10). 2017 Injury Data. NFL.com. https://www.playsmartplaysafe.com/newsroom/reports/2017-injury-data/..

7. Lincoln, A. E., Caswell, S. V., Almquist, J. L., Dunn, R. E., Norris, J. B., \& Hinton, R. Y. (2011). Trends in Concussion Incidence in High School Sports. The American Journal of Sports Medicine, 39(5), 958-963. doi:10.1177/0363546510392326

8. Wilson, T. V. (2021, June 11). How liquid body armor works. HowStuffWorks Science. https://science.howstuffworks.com/liquid-body-armor.htm.

9. "Eric Brown Lab." Eric Brown Lab - Shear Thickening Fluids, www.eng.yale.edu/brown/shearthickening.html.

10. Lin, N. Y., Guy, B. M., Hermes, M., Ness, C., Sun, J., Poon, W. C., \& Cohen, I. (2015). Hydrodynamic and contact contributions to continuous shear thickening in colloidal suspensions. Physical review letters, 115(22), 228304.

11. Gürgen, S., Kuşhan, M. C., \& Li, W. (2017). Shear thickening fluids in protective applications: a review. Progress in Polymer Science, 75, 48-72.

12. Crawford, N. C., Popp, L. B., Johns, K. E., Caire, L. M., Peterson, B. N., \& Liberatore, M. W. (2013). Shear thickening of corn starch suspensions: Does concentration matter?. Journal of colloid and interface science, 396, 83-89. 
13. Hassan, T. A., Rangari, V. K., \& Jeelani, S. (2010). Synthesis, processing and characterization of shear thickening fluid (STF) impregnated fabric composites. Materials Science and Engineering: A, 527(12), 2892-2899.

14. Crisco, J. J., Wilcox, B. J., Beckwith, J. G., Chu, J. J., Duhaime, A., Rowson, S., . . Greenwald, R. M. (2011). Head impact exposure in collegiate football players. Journal of Biomechanics,44(15), 2673-2678. doi:10.1016/j.jbiomech.2011.08.003

15. Wei, M., Sun, L., Zhang, C., Qi, P., \& Zhu, J. (2019). Shear-thickening performance of suspensions of mixed ceria and silica nanoparticles. Journal of Materials Science, 54(1), 346-355.

16. Labaza, C. E. (2014). Improving energy dissipation to lower concussion risk in football helmets (Doctoral dissertation, Massachusetts Institute of Technology).

17. Loadstar Sensors. (2021). https://www.loadstarsensors.com/. 